\title{
Comprehensive quality of life outcomes for pediatric patients undergoing endoscopic sinus surgery*
}

\author{
Robert J. Taylor', Justin D. Miller², Austin S. Rose ${ }^{2}$, Amelia F. Drake², \\ Carlton J. Zdanski², Brent A. Senior'2, Charles S. Ebert Jr.2, \\ Adam M. Zanation² \\ ' Department of Otolaryngology - Head and Neck Surgery, Medical University of South Carolina, Charleston, SC, USA \\ 2 Department of Otolaryngology - Head and Neck Surgery, University of North Carolina, Chapel Hill, NC, USA
}

Rhinology 52: 327-333, 2014

DOl:10.4193/Rhino 14.028

*Received for publication:

February 4, 2014

Accepted: May 23, 2014

\begin{abstract}
Background: Limited quality of life data exist for pediatric chronic rhinosinusitis (CRS) patients undergoing endoscopic sinus surgery (ESS). Further exploration of the following areas will enhance understanding and support clinical decision-making: baseline and post-ESS general and disease-specific quality of life, parent vs. child report, and correlation of nasal endoscopy to sinus CT scores.
\end{abstract}

Methodology: A prospective cohort study evaluated CRS patients age 5-18 undergoing ESS. Surveys were completed at two timepoints: (1) pre-ESS and (2) 30-90 days post-ESS, with parents completing general (PedsQLTM) and CRS-specific (SNOT-16 and SN-5) quality of life surveys and children completing PedsQLTM and SNOT-16 surveys. Preoperative Lund-Kennedy nasal endoscopy and Lund-Mackay sinus CT scores were calculated. Where appropriate, outcomes were stratified by cystic fibrosis status.

Results: Impaired preoperative general quality of life was evidenced by parent proxy-report of PedsQLTM scores in 10 cystic fibrosis and 11 non-CF patients. ESS was associated with decreased sinus symptoms at 1-3 months postoperatively with SN-5 change scores of -1.85 and -2.2 , in CF and non-CF patients, respectively. Parents reported worse CRS symptoms via higher preoperative SNOT-16 scores than their children did. Nasal endoscopy and sinus CT scores correlated with a Spearman correlation coefficient of 0.51. Scores not reaching statistical significance included CF-related CRS SNOT-16 change scores and PedsQLTM general quality of life change scores.

Conclusion: In pediatric patients with CRS electing ESS, general quality of life is impaired preoperatively and sinus symptoms improve significantly 1-3 months after sinus surgery. Parents report statistically worse CRS symptom scores than their children do. Nasal endoscopy scores in this cohort correlated with sinus CT scores.

Key words: sinusitis, pediatrics, quality of life, cystic fibrosis, otolaryngology

\section{Introduction}

Rhinosinusitis is a group of disorders characterized by inflammation of the mucosa of the nose and paranasal sinuses ${ }^{(1)}$. Several forms of rhinosinusitis have been proposed including acute viral/bacterial rhinosinusitis, chronic rhinosinusitis with nasal polyposis (CRSwNP), chronic rhinosinusitis without nasal polyposis (CRSsNP), and allergic fungal rhinosinusitis (AFRS)(2). The etiology of both pediatric and adults CRS is highly debated, but likely results from a multitude of host and environmental factors that produce inflammation of sinonasal mucosa ${ }^{(3)}$. These factors can lead to persistent nasal congestion, discolored nasal discharge, facial pressure/pain, and cough (Table 1) ${ }^{(4)}$. Treatment of pediatric CRS - as described by a recent algorithm ${ }^{(4)}$ - is based on severity of presenting symptoms. Mild symptoms are often treated initially with a trial of nasal saline irrigation and topical nasal steroids, then oral antibiotics for 
persistent symptoms. Moderate and severe symptoms may warrant initial therapy with an oral antibiotic for one or two courses. If oral antibiotics fail, the next step is to consider adenoidectomy \pm intraoperative maxillary sinus irrigation. If symptoms persist or recur after adenoidectomy, then endoscopic sinus surgery is indicated ${ }^{(4)}$. For patients with CRS associated with cystic fibrosis, who are predisposed to mucociliary stasis and bacterial overgrowth ${ }^{(5)}$, surgical treatment is often offered at an earlier age. In surveying the literature, there is limited data evaluating the outcomes of ESS for pediatric CRS. Baseline quality of life in children with CRS is characterized by more bodily pain and physical limitation than children with asthma, rheumatoid arthritis, or epilepsy ${ }^{(6)}$. For these children ESS is safe and effective ${ }^{(7)}$, and CRS-specific quality of life has been shown to improve after ESS ${ }^{(8)}$. In children with CF-related CRS, the evidence suggests that ESS is relatively safe ${ }^{(9)}$, it improves the nasal and facial symptoms of CRS ${ }^{(10)}$, but leads to equivocal change in pulmonary function ${ }^{(11,12)}$ while not altering the respiratory tract microbial pathogens ${ }^{(11)}$.

However, many questions still remain about the impact of pediatric CRS on quality of life and the effect of ESS. It is unclear how parent proxy-report compares to child self-report for both general quality of life and disease-specific quality of life in pediatric CRS patients, and how these metrics change after ESS. Understanding both parent and child perspectives will inform clinical assessment and will provide a comprehensive view of the impact of pediatric CRS and its response to treatment. For objective assessment of pediatric CRS disease severity, it is unknown to what degree nasal endoscopy scores correlate with sinus CT scores, the latter of which is currently well-accepted as the gold-standard for diagnosing CRS in general ${ }^{(13)}$. Previous studies in adults ${ }^{(14,15)}$ have supported the correlation between these two objective measures and it is hypothesized that they will correlate in pediatric CRS.

\section{Materials and methods}

\section{Patient population and selection criteria}

Subjects were recruited consecutively from the otolaryngology clinics at the University of North Carolina at Chapel Hill from 2012-2013. Patients meeting the following criteria were included: ages 5 to 18 at the time of enrolment, diagnosis of CRS (Table 1$)^{(16)}$, CT evidence of sinusitis ${ }^{(17)}$, failure of previous maximal medical treatment including broad-spectrum/culture-directed antibiotics and a trial of nasal steroids, and child/caregiver ability to communicate in English. Patients meeting the following criteria were excluded: gross immunodeficiency, primary ciliary dyskinesia, invasive fungal sinusitis, systemic vasculitis, granulomatous disease, cocaine abuse, and neoplasia.

Ethical approval for this work was obtained through the Institutional Review Board at the University of North Carolina at Chapel Hill. Patients age 5-6 at the onset of the study were enrolled with
Table 1. Defining criteria for chronic rhinosinusitis (CRS) in pediatric patients ${ }^{(4)}$.

$12+$ Weeks of two or more of the following signs and symptoms:

Nasal discharge (anterior, posterior nasal drip, or both) *

Nasal obstruction/congestion/blockage *

Facial pain/pressure/fullness

Cough

* One of the symptoms must be nasal discharge or nasal obstruction.

voluntary informed parental consent. Patients age 7-17 were enrolled with voluntarily self-assent and parental consent. Patients age 18 provided consent for themselves.

Ten patients with CF-related CRS and eleven CRS patients without CF were included in this study. Their demographics and co-morbidities are shown (Table 2).

\section{Data collection}

Patient demographics (age, gender, race/ethnicity parent insurance status, parental educational attainment) and past medical history (polyposis, asthma, allergic rhinitis, smoke exposure, prior adenoidectomy, previous sinus surgeries) were reported by the participants' parents, which was verified with their medical record.

Generic (PedsQLTM Generic Core Scales) and CRS-specific (SN-5 and SNOT-16) quality of life surveys were administered at two timepoints: 1 ) in the two weeks prior to surgery and 2) 1-3 months after surgery. The PedsQLTM Generic Core Scales are a reliable, valid, age-appropriate, and change-responsive measure of general health-related quality of life. They measure the core dimensions of health as delineated by the World Health Organization, as well as role (school) functioning. The physical summary score is calculated from 8 physical items, while the psychosocial summary score is calculated from emotional (5 items), social (5 items), and school functioning (5 items) scales (18-23). The SN-5 survey (Sinus and Nasal Quality of Life 5) is a validated disease-specific measure of $\mathrm{HRQOL}$ in pediatric patients with persistent sinonasal symptoms ${ }^{(24)}$. It contains five domains: sinus infection, nasal obstruction, allergy symptoms, emotional distress, and activity limitations. Each domain consists of a number of symptom clusters and a point scale is used that ranges from 1 (none of the time) to 7 (all of the time) to grade the relative frequency of each symptom cluster to give a mean domain score. The $\mathrm{SN}-5$ has adequate test-retest reliability, is internally consistent, and correlates with related external constructs ${ }^{(25)}$. Per its psychometric validation, it was administered only as a parent-proxy report measure in this study. The SNOT-16 survey is a reliable, valid, and responsive instrument for 
Table 2. Demographics and past medical history of pediatric patients undergoing endoscopic sinus surgery.

\begin{tabular}{|c|c|c|}
\hline Demographic/Comorbidity & CF & Non-CF* \\
\hline Male & 3 & 6 \\
\hline Female & 7 & 5 \\
\hline Age, mean (SD) & $10.8(3.1)$ & $10.9(3.9)$ \\
\hline \multicolumn{3}{|l|}{ Race/Ethnicity } \\
\hline White & 9 & 9 \\
\hline American Indian/Alaskan Native & 1 & 1 \\
\hline Hispanic & 0 & 1 \\
\hline \multicolumn{3}{|l|}{ Parental Education } \\
\hline High School Degree & 3 & 3 \\
\hline Associate's/Bachelor's Degree & 4 & 5 \\
\hline Graduate Degree & 3 & 3 \\
\hline Medicaid & 4 & 3 \\
\hline Private Insurance & 6 & 8 \\
\hline Environmental Allergies, n (\%) & $2(20)$ & $5(45)$ \\
\hline Asthma, n (\%) & $3(30)$ & $8(73)$ \\
\hline Nasal Polyps, n (\%) & $9(90)$ & $4(36)$ \\
\hline Home Tobacco Exposure, n (\%) & $0(0)$ & $2(18)$ \\
\hline History of Adenoidectomy, n (\%) & $2(20)$ & $6(55)$ \\
\hline History of Sinus Surgery, n (\%) & $6(60)$ & $1(9)$ \\
\hline $\begin{array}{l}\text { Number of previous sinus surgeries, } \\
\text { mean (SD)† }\end{array}$ & $2.83(2.2)$ & 1 \\
\hline
\end{tabular}

* Chronic rhinosinusitis in a patient without cystic fibrosis

† Mean number of previous sinus surgeries in patients with a history of sinus surgery

measuring rhinosinusitis-specific health-related quality of life ${ }^{(26)}$. Objective outcomes were recorded preoperatively. Lund-

Mackay sinus CT scores ${ }^{(17)}$ were calculated in a blinded fashion for all patients who had sinus CTs performed within 130 days prior to the surgery, which is a time period that has shown high test-retest reliability ${ }^{(27)}$. This was generally the case since the study institution routinely uses preoperative sinus CTs for surgical planning and intraoperative image-guidance for pediatric ESS. Lund-Kennedy nasal endoscopy scores ${ }^{(28)}$ were calculated by the attending otolaryngologist at the time of surgery after induction of anaesthesia.

\section{Statistical analysis}

To evaluate the change in CRS-specific quality of life, 3 paired ttests compared preoperative to 30-90 days postoperative scores: 1) mean $\mathrm{SN}-5$ scores, 2) total parent proxy-reported SNOT-16 scores, and 3) total child self-reported SNOT-16 scores. To assess the change in general health-related quality of life, 2 paired ttests compared preoperative to 30-90 days postoperative scores: 1) PedsQLTM parent proxy-report and 2) PedsQLTM child selfreport. To compare child self-report of CRS symptoms to parent proxy-report, a paired t-test compared preoperative SNOT-16 child self-reported scores to preoperative SNOT-16 parent proxyreported scores, which subsequently led to a post-hoc analysis investigating the relationship of age - 5 to 11 vs. 12 to 18 - and type of symptom on the difference between parent and child report of CRS-specific symptoms. To investigate the association between Lund-Kennedy nasal endoscopy scores and LundMackay sinus CT scores, a Spearman correlation coefficient was calculated. All statistical analysis was performed on Minitab $16^{\circledR}$ (Minitab Inc., State College, PA, USA) using two-tailed statistical tests.

\section{Results}

For the ten patients with CF-related CRS, individual subjective and objective outcomes are shown (Table 3). For those patients with pre- and post-operative data, the following post-ESS changes were noted: decreased parent-proxy-reported sinus symptoms with SN-5 parent scores decreasing by $1.85(\mathrm{p}=$ $0.001)$, and SNOT-16 parent scores decreasing by $10.4(p=0.02)$. Child self-reported SNOT-16 scores trended toward decreasing symptoms after ESS (-6.4, $\mathrm{p}=0.08)$. Parent proxy-reported and child self-reported PedsQLTM scores trended toward an improvement in general quality of life post-ESS with increases of 5.3 ( $p$ $=0.17)$ and $7.45(p=0.19)$, respectively.

For the eleven CRS patients without CF, individual subjective and objective outcomes are shown in Table 4. For those patients with pre- and post-operative data, the following post-ESS changes were noted: decreased parent-proxy-reported sinus symptoms with SN-5 parent scores decreasing by $2.2(p=0.002)$, SNOT-16 parent scores decreasing by $9.33(p=0.02)$, and child self-reported SNOT-16 scores decreasing by $7.6(p=0.001)$. Parent proxy-reported and child self-reported PedsQLTM scores trended toward an improvement in general quality of life postESS with an increase of $10.3(p=0.052)$ and $4.1(p=0.44)$.

For all participants in the study, parents proxy-reported worse preoperative sinus specific symptoms than their children self-reported ( 24.0 vs. $19.6, p=0.02$ ) with a Pearson correlation of 0.68 $(p=0.001)$. Specific symptoms for which parents reported a statistically significant difference were "blowing nose" (2.1 vs. 1.6, $\mathrm{p}=0.004)$, "thick nasal discharge" (1.4 vs. $0.7, \mathrm{p}=0.02)$, "reduced 
Table 3. Subjective and objective outcomes for patients undergoing endoscopic sinus surgery for chronic rhinosinusitis associated with cystic fibrosis $\neq$.

\begin{tabular}{|c|c|c|c|c|c|c|c|c|c|c|c|c|c|c|}
\hline IDt & Age & Sex & $\begin{array}{c}\text { Preop } \\
\text { SN-5 } \\
\text { Parent }\end{array}$ & $\begin{array}{c}\text { Preop } \\
\text { SNOT- } \\
16 \\
\text { Parent }\end{array}$ & $\begin{array}{c}\text { Preop } \\
\text { SNOT- } \\
16 \\
\text { Child }\end{array}$ & $\begin{array}{l}\text { Preop } \\
\text { Peds- } \\
\text { QLTM } \\
\text { Total } \\
\text { Parent }\end{array}$ & $\begin{array}{l}\text { Preop } \\
\text { Peds- } \\
\text { QLTM } \\
\text { Total } \\
\text { Child }\end{array}$ & $\begin{array}{c}\text { Preop } \\
\text { Sinus } \\
\text { CTף }\end{array}$ & $\begin{array}{l}\text { Preop } \\
\text { Nasal } \\
\text { Endo- } \\
\text { scopy }\end{array}$ & $\begin{array}{c}\text { Postop } \\
\text { SN-5 } \\
\text { Parent }\end{array}$ & $\begin{array}{c}\text { Postop } \\
\text { SNOT- } \\
16 \\
\text { Parent }\end{array}$ & $\begin{array}{c}\text { Postop } \\
\text { SNOT- } \\
16 \\
\text { Child }\end{array}$ & $\begin{array}{c}\text { Postop } \\
\text { Peds- } \\
\text { QL'M }^{\text {TM }} \\
\text { Total } \\
\text { Parent }\end{array}$ & $\begin{array}{c}\text { Postop } \\
\text { Peds- } \\
\text { QL' } \\
\text { Total } \\
\text { Child }\end{array}$ \\
\hline 1 & 6 & $M$ & 4.4 & 13 & 1 & 84.4 & 89.1 & 9 & 12 & 2.8 & 9 & 1 & 78.3 & 93.5 \\
\hline 2 & 6 & $\mathrm{~F}$ & 3.6 & 9 & 20 & 87.0 & 78.3 & 4 & 10 & * & * & * & * & * \\
\hline 3 & 9 & $\mathrm{~F}$ & 5.2 & 29 & 18 & 73.9 & 77.2 & $\S$ & 10 & 2.4 & 19 & 14 & 73.9 & 83.7 \\
\hline 4 & 10 & $M$ & 4.2 & 19 & 9 & 77.2 & 92.4 & $\S$ & 12 & 4.6 & 14 & 0 & 72.8 & 97.8 \\
\hline 5 & 11 & $\mathrm{~F}$ & 6.4 & 39 & 29 & 31.5 & 50.0 & 12 & 9 & * & * & * & * & * \\
\hline 6 & 12 & $\mathrm{~F}$ & 5.0 & 30 & 20 & 59.8 & 84.8 & 16.4 & 13 & 3.4 & 8 & 16 & 81.5 & 84.8 \\
\hline 7 & 12 & $\mathrm{~F}$ & 3.6 & 15 & 5 & 92.4 & 93.5 & 21.8 & 7 & 1.4 & 7 & 1 & 91.3 & 95.7 \\
\hline 8 & 13 & $M$ & 5.0 & 33 & 29 & 59.8 & 56.5 & 13 & 5 & 2.2 & 13 & 6 & 70.7 & 93.5 \\
\hline 9 & 14 & $\mathrm{~F}$ & 4.4 & 16 & 8 & 85.9 & 83.7 & 23 & 10 & 2.2 & 5 & 10 & 93.5 & 88.0 \\
\hline 10 & 15 & $\mathrm{~F}$ & 4.2 & 10 & 6 & 90.2 & 94.6 & 16 & 8 & 2.2 & 5 & 10 & 93.5 & 88.0 \\
\hline Mean & 10.8 & & 4.6 & 21.3 & 14.5 & 74.2 & 80.0 & 14.4 & 9.6 & 2.7 & 11 & 6.38 & 81.8 & 91.0 \\
\hline SD & (3.1) & & $(0.84)$ & (10.6) & (10.1) & (19.0) & (15.4) & (6.3) & $(2.5)$ & $(1.0)$ & (4.6) & (6.3) & (9.4) & $(5.1)$ \\
\hline
\end{tabular}

₹ Scores rounded to the nearest tenth where appropriate. All analysis performed on raw unrounded scores. † Patient ID sorted by age from youngest to oldest. ๆ For patients with absent frontal sinuses, total Lund-Mackay sinus CT scores were converted to a 24 point scale, ${ }^{*}$ Lost to follow-up, $\S$ Performed $>130$ days prior to surgery.

productivity" (1.3 vs. $0.7, \mathrm{p}=0.003)$, and "reduced concentration" (1.2 vs. $0.8, p=0.009)$. When total SNOT-16 scores were stratified by age, there was no statistical difference between parent and child report for 5-11 year old participants ( 23.9 vs. $21.3, p=0.31$ ), but there was a difference between parent and child report for $12-18$ year olds ( 24.1 vs. $17.3, p=0.01$ ). There was no significant difference between parent proxy-report and child self-report of general quality of life (72.9 vs. $73.7, p=0.78)$.

The Pearson correlation of Lund-Mackay sinus CT scores with Lund-Kennedy nasal endoscopy scores for all patients undergoing ESS for CRS was 0.51 ( $p=0.04$; Figure 1).

\section{Discussion}

This data shows that children with chronic rhinosinusitis (CRS) \pm cystic fibrosis that failed maximal medical therapy and elected endoscopic sinus surgery (ESS) have impaired pre-ESS general quality of life and improve their CRS-specific symptoms 1-3 months post-ESS. Additionally, in these patients pre-ESS nasal endoscopy scores correlate with sinus CT scores, and parents proxy-report worse CRS symptoms than their children self-

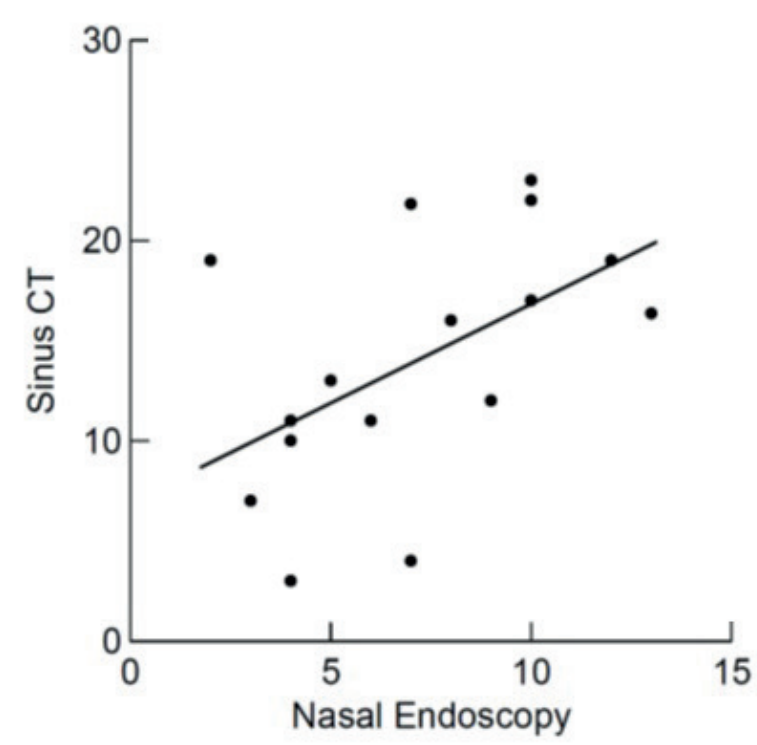

Figure 1. Correlation of preoperative Lund-Mackay sinus CT scores with Lund-Kennedy nasal endoscopy scores in pediatric patients undergoing endoscopic sinus surgery for chronic rhinosinusitis, Spearman correlation coefficient $=0.51(p=0.04)$. 
Table 4. Subjective and objective outcomes for patients without cystic fibrosis undergoing endoscopic sinus surgery for chronic rhinosinusitis $\neq$.

\begin{tabular}{|c|c|c|c|c|c|c|c|c|c|c|c|c|c|c|}
\hline IDt & Age & Sex & $\begin{array}{c}\text { Preop } \\
\text { SN-5 } \\
\text { Parent }\end{array}$ & $\begin{array}{c}\text { Preop } \\
\text { SNOT- } \\
16 \\
\text { Parent }\end{array}$ & $\begin{array}{c}\text { Preop } \\
\text { SNOT- } \\
16 \\
\text { Child }\end{array}$ & $\begin{array}{c}\text { Preop } \\
\text { Peds- } \\
\text { QLTM } \\
\text { Total } \\
\text { Parent }\end{array}$ & $\begin{array}{l}\text { Preop } \\
\text { Peds- } \\
\text { QLTM } \\
\text { Total } \\
\text { Child }\end{array}$ & $\begin{array}{c}\text { Preop } \\
\text { Sinus } \\
\text { CTI }\end{array}$ & $\begin{array}{l}\text { Preop } \\
\text { Nasal } \\
\text { Endo- } \\
\text { scopy }\end{array}$ & $\begin{array}{c}\text { Postop } \\
\text { SN-5 } \\
\text { Parent }\end{array}$ & $\begin{array}{c}\text { Postop } \\
\text { SNOT- } \\
16 \\
\text { Parent }\end{array}$ & $\begin{array}{c}\text { Postop } \\
\text { SNOT- } \\
16 \\
\text { Child }\end{array}$ & $\begin{array}{c}\text { Postop } \\
\text { Peds- } \\
\text { QL'M } \\
\text { Total } \\
\text { Parent }\end{array}$ & $\begin{array}{c}\text { Postop } \\
\text { Peds- } \\
\text { QLM } \\
\text { Total } \\
\text { Child }\end{array}$ \\
\hline 11 & 7 & $M$ & 4.2 & 32 & 27 & 73.9 & 47.8 & 11 & 4 & 4 & 27 & 14 & 77.2 & 70.7 \\
\hline 12 & 7 & $M$ & 4.8 & 29 & 37 & 43.5 & 19.6 & $\S$ & 5 & * & * & * & * & * \\
\hline 13 & 7 & $M$ & 4.6 & 13 & 25 & 64.1 & 63.0 & $\S$ & 7 & 4 & 24 & 14 & 75.0 & 89.1 \\
\hline 14 & 7 & $M$ & 6.0 & 32 & 24 & 79.4 & 69.6 & $\S$ & 4 & 1.2 & 10 & 18 & 80.4 & 67.4 \\
\hline 15 & 10 & $M$ & 4.6 & 22 & 18 & 89.1 & 90.2 & $\S$ & 2 & 1.4 & 3 & 5 & 98.9 & 89.1 \\
\hline 16 & 11 & $\mathrm{~F}$ & 4.0 & 17 & 15 & 100.0 & 97.8 & 19 & 2 & 1.8 & 4 & 9 & 100 & 88.0 \\
\hline 17 & 11 & $\mathrm{~F}$ & 4.8 & 33 & 32 & 60.9 & 60.9 & 22 & 10 & 3.2 & 30 & 31 & 67.4 & 41.3 \\
\hline 18 & 12 & $\mathrm{~F}$ & 5.2 & 29 & 18 & 68.5 & 67.4 & 7 & 3 & 4.2 & 18 & 15 & 73.9 & 66.3 \\
\hline 19 & 13 & $\mathrm{~F}$ & 6.4 & 45 & 27 & 59.8 & 68.5 & 3 & 4 & 4 & 37 & 24 & 70.7 & 72.8 \\
\hline 20 & 17 & $\mathrm{~F}$ & 5.2 & 15 & 16 & 54.4 & 81.5 & 17 & 10 & 1.6 & 1 & 4 & 98.9 & 98.9 \\
\hline 21 & 18 & $M$ & 4.4 & 24 & 27 & 94.6 & 81.5 & 11 & 6 & * & * & * & * & * \\
\hline Mean & 10.9 & & 4.9 & 26.5 & 24.2 & 71.6 & 68.0 & 12.9 & 5.2 & 2.8 & 17.1 & 14.9 & 82.5 & 76.0 \\
\hline SD & (3.9) & & $(0.7)$ & $(9.4)$ & (6.9) & (17.7) & (21.4) & (6.8) & $(2.8)$ & (1.3) & (4.6) & (8.7) & (13.1) & (17.4) \\
\hline
\end{tabular}

₹ Scores rounded to the nearest tenth where appropriate. All analysis performed on raw unrounded scores. † Patient ID sorted by age from youngest to oldest. ๆ For patients with absent frontal sinuses, total Lund-Mackay sinus CT scores were converted to a 24 point scale, ${ }^{*}$ Lost to follow-up, $\S$ Performed $>130$ days prior to surgery.

report. These findings are strengthened by the study's prospective design and use of multiple instruments assessing similar quality of life domains. However, the study is limited by its lack of randomization or blinding. The pediatric patients whom an otolaryngologist recommends to undergo ESS for CRS are not representative of the entire CRS population. It is possible that subjects who undergo surgery may have worse preoperative disease severity, more financial resources, and more motivation to seek effective treatment outcomes. The lack of blinding in the study also introduces bias. By knowing whether surgery has been performed, the parent and child may have a higher expectation of benefit than if they were to receive only medical therapy. Furthermore, these conclusions must take into account the small sample size of this study, which limits its generalizability.

It is generally believed that patients with CRS who fail medical therapy and elect ESS have impaired general quality of life preoperatively ${ }^{(6,25)}$. The results of the present study corroborate these prior results. Parent PedsQLTM proxy-report scores trended toward a lower quality of life for this study's patients with CF
(74.24) and without it (71.6), as compared to published values for a healthy population (81.34) ${ }^{(19)}$. Similarly, child PedsQLTM self-report scores trended toward a lower quality of life for this study's patients with CF (80.0) and without it (68.0) as compared to published values for a healthy population $(82.87)^{(19)}$.

This study's observed improvement in CRS-specific quality of life in pediatric patients electing ESS is consistent with the literature in patients with ${ }^{(29)}$ and without ${ }^{(7,8,30)}$ CF. For CRS patients without $\mathrm{CF}$, of note, this study is the first to show that improvement from the perspective of both the parent (SNOT-16 and SN-5) and child (SNOT-16). In the CF-related CRS group, these results were similar-improved symptom scores based on parent $\mathrm{SN}-5$ and SNOT-16 proxy-report-but the child self-reported SNOT-16 scores did not reach statistical significance. These results agree with other studies of CF patients with CRS undergoing ESS in pediatric ${ }^{(31)}$ and mixed pediatric/young adult populations ${ }^{(10,32,33)}$, as reviewed by MacDonald et al. ${ }^{(34)}$. These points are made cautiously, noting that there is no non-surgical comparison group in the present studies or the cited studies to assess the natural course of the disease. Furthermore, it should be noted in 
the present study that while the SNOT-16 has been validated in adult populations ${ }^{(26)}$ and studied in a pediatric population with cystic fibrosis ${ }^{(35)}$, it has not been specifically validated in the pediatric population of patients with CRS. Despite this limitation, the authors believe the SNOT-16 is a reasonable measure of CRS disease severity. This is supported by the difference between this study's preoperative SNOT-16 scores to a group of patients without sinus disease's SNOT-16 scores of $10.5^{(26)}$. Additionally, the change in the SNOT-16 scores post-ESS as described provides evidence for the instrument's responsiveness to treatment.

This is the first study to show a correlation between nasal endoscopy and sinus CT for pediatric patients with CRS. This supports the current practice of attempting nasal endoscopy to diagnose pediatric CRS and monitor disease course, when the child will tolerate the procedure. Postoperative monitoring of disease status with nasal endoscopy before a sinus $\mathrm{CT}$ is performed may be especially important in CF-related CRS, since these patients are more likely to develop CRS recurrence and are more likely to receive diagnostic radiation during their lifetimes ${ }^{(36)}$.

The difference between parent proxy- and child self-report for CRS has been described in one other study, which observed parents proxy-reporting worse bodily pain, general health, and general behaviour effects than their children self-reported ${ }^{(6)}$. The true reason why parents are proxy-reporting worse symptoms than their children is unclear. It is conceivable that the parents have more insight into the disease process and abstract reasoning than their children. Alternatively, it has been suggested that the patients who receive more CRS care may have a family member who, "is uncommonly focused on, and intolerant of sinus symptoms (37)." Another possibility is that parents may be more motivated for accurately reporting health information than their children. Altogether, future qualitative studies are needed to answer this question. Until then, it is relevant for the clinician to know that parents may proxy-report worse CRS symptoms than their children self-report.

\section{Conclusion}

Children with CRS \pm cystic fibrosis undergoing endoscopic sinus surgery (ESS) have an impaired general quality of life pre-ESS. CRS-specific quality of life improves 1-3 months post-ESS, preoperative nasal endoscopy scores correlate with sinus CT scores, and parents proxy-report worse CRS-specific quality of life scores than their children self-report.

\section{Acknowledgements}

This work was supported by a grant from the Doris Duke Charitable Foundation to the University of North Carolina-Chapel Hill to fund Clinical Research Fellow Robert Taylor. The general quality of life instrument - the PedsQLTM - was developed by Dr. James W. Varni. Permission to use it was granted. This work was performed at University of North Carolina Hospitals, University of North Carolina-Chapel Hill. Presented at the 59th Annual Meeting of the American Rhinologic Society, Sept 28, 2013.

\section{Authorship contribution}

RJT: study coordinator, data analysis, manuscript preparationJDM: data collection; ASR: data collection; AFD: data collection; CJZ: data collection; BAS: study design, manuscript preparation; CSE: study design, manuscript preparation; AMZ: principle investigator, study design, data analysis, manuscript preparation.

\section{Conflicts of Interest}

None

\section{References}

1. Benninger MS, Ferguson BJ, Hadley JA, et al. Adult chronic rhinosinusitis: definitions, diagnosis, epidemiology, and pathophysiology. Otolaryngol Head Neck Surg. 2003; 129: S1-32.

2. Meltzer EO, Hamilos DL, Hadley JA, et al. Rhinosinusitis: Establishing definitions for clinical research and patient care. Otolaryngol Head Neck Surg. 2004; 131 : S1-62.

3. Lusk R. Pediatric chronic rhinosinusitis. Curr Opin Otolaryngol Head Neck Surg. 2006; 14:393-396.

4. Fokkens WJ, Lund VJ, Mullol J, et al. European Position Paper on Rhinosinusitis and Nasal Polyps 2012. Rhinology Supplement 23; 2012: 1-298.

5. Mainz JG, Koitschev A. Management of chronic rhinosinusitis in CF. J Cyst Fibros. 2009; 8 Suppl 1:S10-14.

6. Cunningham JM, Chiu EJ, Landgraf JM, Gliklich RE. The health impact of chron- ic recurrent rhinosinusitis in children. Arch Otolaryngol Head Neck Surg. 2000; 126:1363-1368.

7. Hebert RL, 2nd, Bent JP, 3rd. Meta-analysis of outcomes of pediatric functional endoscopic sinus surgery. Laryngoscope 1998; 108: 796-799

8. Rudnick EF, Mitchell RB. Long-term improvements in quality-of-life after surgical therapy for pediatric sinonasal disease. Otolaryngol Head Neck Surg. 2007; 137: 873-877.

9. Albritton FD, Kingdom TT. Endoscopic sinus surgery in patients with cystic fibrosis: an analysis of complications. Am J Rhinol. 2000; 14: 379-385.

10. Keck T, Rozsasi A. Medium-term symptom outcomes after paranasal sinus surgery in children and young adults with cystic fibrosis. Laryngoscope. 2007; 117: 475-479.

11. Osborn AJ, Leung R, Ratjen F, James AL. Effect of endoscopic sinus surgery on pulmonary function and microbial pathogens in a pediatric population with cystic fibrosis. Arch Otolaryngol Head Neck Surg. 2011; 137: 542-547

12. Kovell LC, Wang J, Ishman SL, Zeitlin PL, Boss EF. Cystic fibrosis and sinusitis in children: outcomes and socioeconomic status. Otolaryngol Head Neck Surg. 2011; 145: 146-153.

13. Bhattacharyya N, Jones DT, Hill M, Shapiro NL. The diagnostic accuracy of computed tomography in pediatric chronic rhinosinusitis. Arch Otolaryngol Head Neck Surg. 2004; 130: 1029-1032.

14. Kaplan BA, Kountakis SE. Role of nasal endoscopy in patients undergoing endoscopic sinus surgery. Am J Rhinol. 2004; 18: 161-164.

15. Smith $T L$, Rhee JS, Loehrl TA, Burzynski ML, Laud PW, Nattinger AB. Objective testing and quality-of-life evaluation in surgical candidates with chronic rhinosinusitis. Am J Rhinol . 2003; 17: 351-356.

16. Rosenfeld RM, Andes D, Bhattacharyya N, et 
al. Clinical practice guideline: adult sinusitis Otolaryngol Head Neck Surg. 2007; 137: S1-31.

17. Lund VJ, Mackay IS. Staging in rhinosinusitus. Rhinology 1993; 31: 183-184.

18. Chan KS, Mangione-Smith R, Burwinkle TM Rosen M, Varni JW. The PedsQL: reliability and validity of the short-form generic core scales and Asthma Module. Med care 2005; 43: 256-265.

19. Varni JW, Burwinkle TM, Seid M, Skarr D. The PedsQL 4.0 as a pediatric population health measure: feasibility, reliability, and validity. Ambul Pediatr. 2003; 3: 329-341.

20. Varni JW, Limbers CA. The PedsQL 4.0 Generic Core Scales Young Adult Version: feasibility, reliability and validity in a university student population. J Health Psychol. 2009; 14: 611-622.

21. Varni JW, Seid M, Knight TS, Uzark K, Szer IS. The PedsQL 4.0 Generic Core Scales: sensitivity, responsiveness, and impact on clinical decision-making. J Behav Med. 2002; 25 175-193.

22. Varni JW, Seid M, Kurtin PS. PedsQL 4.0: reliability and validity of the Pediatric Quality of Life Inventory version 4.0 generic core scales in healthy and patient populations. Med Care. 2001; 39: 800-812.

23. Varni JW, Seid M, Rode CA. The PedsQL: measurement model for the pediatric quality of life inventory. Med. Care 1999; 37: 126-139.

24. Solans M, Pane S, Estrada MD, et al. Healthrelated quality of life measurement in children and adolescents: a systematic review of generic and disease-specific instruments. Value Health. 2008; 11:742-764.

25. Kay DJ, Rosenfeld RM. Quality of life for chil- dren with persistent sinonasal symptoms. Otolaryngol Head Neck Surg. 2003; 128 : 17-26.

26. Anderson ER, Murphy MP, Weymuller EA, Jr. Clinimetric evaluation of the Sinonasal Outcome Test-16. Student Research Award 1998. Otolaryngol Head Neck Surg. 1999; 121: 702-707.

27. Bhattacharyya N. Test-retest reliability of computed tomography in the assessment of chronic rhinosinusitis. Laryngoscope 1999; 109: 1055-1058.

28. Lund VJ, Kennedy DW. Staging for rhinosinusitis. Otolaryngol Head Neck Surg. 1997; 117: S35-40

29. Jones JW, Parsons DS, Cuyler JP. The results of functional endoscopic sinus (FES) surgery on the symptoms of patients with cystic fibrosis. Int J Pediat Otorhinolaryngol. 1993; 28: 25-32.

30. Makary CA, Ramadan HH. The role of sinus surgery in children. Laryngoscope. 2013; 123: 1348-1352

31. Triglia JM, Nicollas R. Nasal and sinus polyposis in children. Laryngoscope. 1997; 107: 963-966.

32. Aanaes K, Johansen HK, Skov M, et al. Clinical effects of sinus surgery and adjuvant therapy in cystic fibrosis patients - can chronic lung infections be postponed? Rhinology. 2013; 51: 222-230.

33. Nishioka GJ, Barbero GJ, Konig P, Parsons DS, Cook PR, Davis WE. Symptom outcome after functional endoscopic sinus surgery in patients with cystic fibrosis: a prospective study. Otolaryngol Head Neck Surg. 1995; 113: 440-445.

34. Macdonald Kl, Gipsman A, Magit A, et al. Endoscopic sinus surgery in patients with cystic fibrosis: A systematic review and meta-analysis of pulmonary function. Rhinology 2012; 50: 360-369.

35. Friedman EM, Stewart M. An assessment of sinus quality of life and pulmonary function in children with cystic fibrosis. Am J Rhinol. 2006; 20: 568-572

36. Cavel O, Quintal MC, Marcotte JE, Garel $L$, Froehlich P. Restricting indications for sinonasal computed tomography in children with cystic fibrosis. JAMA Otolaryngol Head Neck Surg. 2013; 139: 54-58.

37. Pensak ML. Controversies în otolaryngology. Thieme, 2001

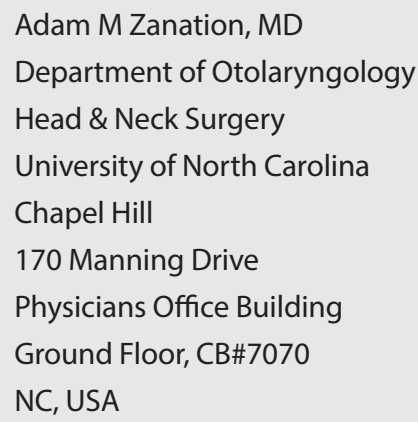

Adam M Zanation, MD

Department of Otolaryngology

Head \& Neck Surgery

University of North Carolina

Chapel Hill

170 Manning Drive

Physicians Office Building

Ground Floor, CB\#7070

NC, USA

Tel: +1-919-966-3342

Fax: +1-919-933-7941

Email:adam_zanation@med.unc.edu 